\title{
A micronised, dispersible ferric pyrophosphate with high relative bioavailability in man
}

\author{
Meredith C. Fidler ${ }^{1}$, Thomas Walczyk ${ }^{1}$, Lena Davidsson ${ }^{1 *}$, Christophe Zeder ${ }^{1}$, \\ Noboru Sakaguchi ${ }^{2}$, Lekh R. Juneja ${ }^{2}$ and Richard F. Hurrell ${ }^{1}$ \\ ${ }^{1}$ Laboratory for Human Nutrition, Institute of Food Science and Nutrition, Swiss Federal Institute of Technology \\ (ETH) Zurich, PO Box 474/Seestrasse 72, CH-8803 Rüschlikon, Switzerland \\ ${ }^{2}$ Nutritional Foods Division, Taiyo Kagaku, 9-5 Akahori-Shinmachi, Yokkaichi, Mie 510-0825, Japan
}

(Received 14 May 2003 - Revised 4 September 2003 - Accepted 10 September 2003)

\begin{abstract}
Ferric pyrophosphate is a water-insoluble Fe compound used to fortify infant cereals and chocolate-drink powders as it causes no organoleptic changes to the food vehicle. However, it is only of low absorption in man. Recently, an innovative ferric pyrophosphate has been developed (Sunactive $\mathrm{Fe}^{\mathrm{TM}}$ ) based on small-particle-size ferric pyrophosphate (average size $0.3 \mu \mathrm{m}$ ) mixed with emulsifiers, so that it remains in suspension in liquid products. The aim of the present studies was to compare Fe absorption of micronised, dispersible ferric pyrophosphate (Sunactive $\mathrm{Fe}^{\mathrm{TM}}$ ) with that of ferrous sulfate in an infant cereal and a yoghurt drink. Two separate Fe absorption studies were made in adult women (ten women/study). Fe absorption was based on the erythrocyte incorporation of stable isotopes $\left({ }^{57} \mathrm{Fe}\right.$ and $\left.{ }^{58} \mathrm{Fe}\right) 14 \mathrm{~d}$ after the intake of labelled test meals of infant cereal (study 1) or yoghurt drink (study 2). Each test meal was fortified with $5 \mathrm{mg}$ Fe as ferrous sulfate or micronised, dispersible ferric pyrophosphate. Results are presented as geometric means. There was no statistically significant difference between Fe absorption from micronised, dispersible ferric pyrophosphate- and ferrous sulfate-fortified infant cereal (3.4 and $4.1 \%$ respectively; $P=0.24)$ and yoghurt drink (3.9 and $4.2 \%$ respectively; $P=0.72)$. The results of the present studies show that micronised, dispersible ferric pyrophosphate is as well absorbed as ferrous sulfate in adults. The high relative Fe bioavailability of micronised, dispersible ferric pyrophosphate indicates the potential usefulness of this compound for food fortification.
\end{abstract}

Iron absorption: Iron fortification: Ferric pyrophosphate: Sunactive $\mathrm{Fe}^{\mathrm{TM}}$

Food fortification programmes are usually considered the most cost-effective and sustainable approach to combat $\mathrm{Fe}$ deficiency. However, the success of an Fe fortification programme depends largely on the careful choice of the Fe compound (Hurrell, 1997, 1998). A cheap and highly bioavailable $\mathrm{Fe}$ compound that causes no organoleptic changes would be the ideal fortification compound. Unfortunately, the water-soluble compounds, which are the most bioavailable, for example, ferrous sulfate, often cause unacceptable colour or flavour changes in the food vehicle (Hurrell \& Cook, 1990). Ferric pyrophosphate is a water-insoluble $\mathrm{Fe}$ compound often used by European food companies to fortify infant cereals and chocolatedrink powders. Its main advantage is that it causes no adverse colour and flavour changes to food vehicles. However, it is only poorly soluble in dilute acid, such as the gastric juice, and is thus only of mediocre absorption in man. Human studies have reported absorption values between 15 and $75 \%$ relative to ferrous sulfate, depending on batch and processing (Hurrell et al. 1989, 1991, 2000). A further disadvantage of ferric pyrophosphate is that it cannot be used to fortify liquid products due to its water insolubility.

Recently, a micronised, dispersible ferric pyrophosphate has been developed for food fortification. This innovative compound (Sunactive $\mathrm{Fe}^{\mathrm{TM}}$; Taiyo Kagaku (Yokkaichi, Japan) is produced from ferric chloride and sodium pyrophosphate using a dispersion technique resulting in ferric pyrophosphate particles of very small average size (approximately $0.3 \mu \mathrm{m}$ ). Further, the formation of agglomerates is avoided by adding emulsifiers. This has the additional advantage that the micronised ferric pyrophosphate is dispersible in aqueous solutions and can be used to fortify liquid foods or drinks such as milk. Micronised, dispersible ferric pyrophosphate has been reported to have a similar bioavailability as ferrous sulfate in rat $\mathrm{Hb}$ repletion studies (Juneja et al. 2003).

The aim of the present study was to compare Fe absorption from micronised, dispersible ferric pyrophosphate (Sunactive $\mathrm{Fe}^{\mathrm{TM}}$ ) with ferrous sulfate. $\mathrm{Fe}$ absorption was measured in healthy women from a wheat-based infant cereal and a yoghurt drink by using a stable-isotope

\footnotetext{
Abbreviation: RBV, relative bioavailability.

* Corresponding author: Dr Lena Davidsson, fax +41 170457 10, email lena.davidsson@ilw.agrl.ethz.ch
} 
technique based on the incorporation of Fe stable isotopes into erythrocytes $14 \mathrm{~d}$ after administration.

\section{Subjects and methods}

\section{Subjects}

Twenty apparently healthy adult women (20-30 years; maximum body weight $60 \mathrm{~kg}$ ) were recruited from the student and staff population at the Swiss Federal Institute of Technology Zurich and the University of Zurich. The subjects were randomly allocated into two separate studies (ten subjects/study). Exclusion criteria included pregnancy or lactation and known gastrointestinal or metabolic disorders. No medication (except oral contraceptives) or vitamin and mineral supplements were allowed during the study. Women regularly taking vitamin and mineral supplements discontinued the supplementation 2 weeks before the start of the study.

The study protocol was reviewed and approved by the ethical committee at the Swiss Federal Institute of Technology Zurich, Switzerland. Subjects were informed orally and in writing about the aims and procedures of the study. Written informed consent was obtained from all study subjects.

\section{Study design}

Fe absorption was based on erythrocyte incorporation of Fe stable-isotope labels $14 \mathrm{~d}$ after the intake of labelled test meals. The Fe compounds were labelled with ${ }^{57} \mathrm{Fe}$ or ${ }^{58} \mathrm{Fe}$ and added to the different test meals as described later. All test meals were fed, after an overnight fast, on two consecutive days under strictly standardised conditions and close supervision. A crossover study design was used with each woman acting as her own control. On the day before the intake of the first test meal (day 0), a venous blood sample was drawn after an overnight fast for the determination of $\mathrm{Fe}$ status parameters $(\mathrm{Hb}$, and plasma ferritin) and body weight and height were measured. The two test meals were fed on the following days (days 1 and 2) between 07.00 and 09.00 hours. No intake of food or fluids was allowed for $3 \mathrm{~h}$ after the test-meal intake. A second venous blood sample was drawn $14 \mathrm{~d}$ after the intake of the second test meal (day 16).

\section{Test meals}

The test meals in study 1 consisted of $50 \mathrm{~g}$ roller-dried wheat-based infant cereal (Nestlé PTC, Orbe, Switzerland) fed with reconstituted milk (8g Sano Lait milk powder; Coop Schweiz, Basel, Switzerland, and $75 \mathrm{ml}$ deionised water). The infant cereal was made from $79.7 \%$ partially hydrolysed wheat flour, $10 \%$ sucrose, $4 \%$ honey, $3 \%$ palm oil, $0.3 \%$ calcium carbonate and $3 \%$ water. Except for $\mathrm{Ca}$, no minerals or vitamins were added. The test meals in study 2 consisted of a yoghurt drink made from $170 \mathrm{~g}$ unskimmed yoghurt (Joghurt Nature $3.5 \%$ fat; Migros Bio, Zurich, Switzerland) and $100 \mathrm{~g}$ unskimmed milk (Valflora 3.8\% fat; Migros, Zurich, Switzerland). Each test meal contained $5 \mathrm{mg}$ added $\mathrm{Fe}, 4 \mathrm{mg} \mathrm{Fe}$ as
${ }^{58} \mathrm{FeSO}_{4}$ plus $1 \mathrm{mg} \mathrm{Fe}$ as $\mathrm{FeSO}_{4}$ of natural isotopic composition or $5 \mathrm{mg} \mathrm{Fe}$ as micronised, dispersible $\left[{ }^{57} \mathrm{Fe}\right]$ ferric pyrophosphate. Deionised water $(200 \mathrm{~g})$ was served as a drink in study 1 .

\section{Stable isotope labels}

$\left[{ }^{58} \mathrm{Fe}\right]$ ferrous sulfate was prepared from isotopically enriched elemental Fe (Chemgas, Boulogne, France) by dissolution in sulfuric acid and dilution to the appropriate concentration. Micronised, dispersible $\left[{ }^{57} \mathrm{Fe}\right]$ ferric pyrophosphate was prepared from isotopically enriched elemental $\mathrm{Fe}$ (Chemgas, Boulogne, France) by firstly dissolving the elemental $\mathrm{Fe}$ in concentrated $\mathrm{HCl}$. Formed ${ }^{57} \mathrm{FeCl}_{2}$ was oxidised to ${ }^{57} \mathrm{FeCl}_{3}$ by the addition of $\mathrm{H}_{2} \mathrm{O}_{2}(30 \%$, v/v). To remove impurities (iron oxides), the soluble ${ }^{57} \mathrm{FeCl}_{3}$ was extracted into diethyl ether, followed by re-extraction into deionised water. This $\mathrm{FeCl}_{3}$ solution was evaporated under vacuum at $80^{\circ} \mathrm{C}$ using a rotorvap (Rotavapor; Buechi, Flawil, Switzerland). Thereafter, the resulting dark red paste was crystallised to bright yellow ${ }^{57} \mathrm{FeCl}_{3} \cdot 6 \mathrm{H}_{2}$ $\mathrm{O}$. From this base compound, micronised, dispersible $\left[{ }^{57} \mathrm{Fe}\right]$ ferric pyrophosphate was produced by Taiyo Kagaku (Yokkaichi, Japan) by mixing ${ }^{57} \mathrm{FeCl}_{3} \cdot 6 \mathrm{H}_{2} \mathrm{O}$, emulsifiers (enzymically hydrolysed soya lecithin and polyglycerol fatty acid ester) and sodium pyrophosphate (Nanbu et al. 1998). Particle size was measured using a submicron particle sizer (NiComp 370; Particle Sizing Systems, Santa Barbara, CA, USA) and the labelled compound was found to be equivalent to commercial Sunactive $\mathrm{Fe}^{\mathrm{TM}}$ with respect to particle-size distribution (average particle size $0.24 \mu \mathrm{m}$; Fig. 1) and visual appearance. As a comparison, the particle-size distribution of a commercial food-grade ferric pyrophosphate (Dr Paul Lohmann Ltd, Emmerthal, Germany) was measured by laser light diffraction (Mastersizer X; Malvern Instruments Ltd, Malvern, UK; Fig. 1).

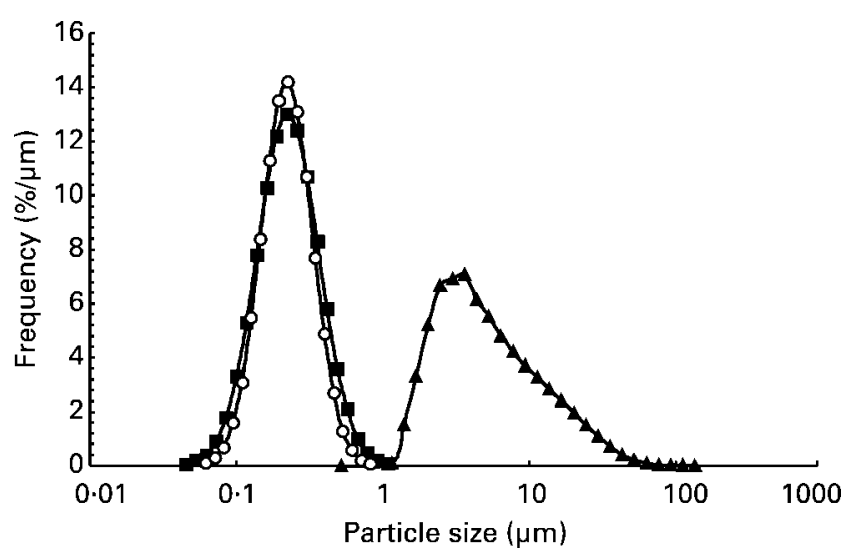

Fig. 1. Particle-size distribution shown as relative volume percentage frequency curve of ${ }^{57} \mathrm{Fe}$-labelled micronised, dispersible ferric pyrophosphate $\left({ }^{57} \mathrm{Fe}\right.$ Sunactive $\mathrm{Fe}^{\mathrm{TM}}$; Taiyo Kagaku, Yokkaichi, Japan) (-O-). For comparison, the particle-size distribution of commercial micronised, dispersible ferric pyrophosphate (Sunactive $\mathrm{Fe}^{\mathrm{TM}}$; Taiyo Kagaku, Yokkaichi, Japan) (-口-) and commercial ferric pyrophosphate (Dr Paul Lohmann Ltd, Emmerthal, Germany) (-^-) are shown. Particle-size distribution was measured by laser diffraction (NiComp 370; Particle Sizing Systems, Santa Barbara, CA, USA and Mastersizer X; Malvern Instruments Ltd, Malvern, UK). 


\section{Quantification of iron isotopes in labelled iron fortificants}

Isotope-dilution MS was used to determine the concentration of ${ }^{57} \mathrm{Fe}$ and ${ }^{58} \mathrm{Fe}$ stable isotopes in the micronised, dispersible ferric pyrophosphate and ferrous sulfate solutions. An accurately measured amount of $\mathrm{Fe}$ of natural isotopic composition was added to samples taken from the prepared solutions of labelled Fe fortificants. The $\mathrm{Fe}$ standard was prepared gravimetrically from an isotopic reference material (IRMM-014; EU Institute of Reference Materials, Geel, Belgium). Isotopic analysis was performed using negative thermal ionisation MS (Walczyk, 1997). $\mathrm{Fe}$ concentrations in each labelled $\mathrm{Fe}$ fortificant solution were calculated based on the shift in $\mathrm{Fe}$ isotopic abundances, the determined isotopic abundances of the pure isotopic labels and the natural Fe isotopic abundances (Walczyk et al. 1997).

\section{Iron status measurements}

Venous blood samples $(7 \mathrm{ml})$ were drawn in EDTA-treated tubes at each sampling. Samples were analysed for Fe status indices $(\mathrm{Hb}$, plasma ferritin) and for the incorporation of ${ }^{57} \mathrm{Fe}$ and ${ }^{58} \mathrm{Fe}$ into erythrocytes (day 16 ). Whole blood samples were portioned for the analysis of $\mathrm{Hb}$ and isotopic composition and plasma was separated, sampled and frozen for the later analysis of plasma ferritin. $\mathrm{Hb}$ was measured by the cyanmethaemoglobin method (Sigma kit; Sigma, St Louis, MO, USA) and plasma ferritin by ELISA (Ramco Laboratories, Houston, TX, USA). Commercial qualitycontrol materials (DiaMed, Cressier sur Morat, Switzerland and Ramco Laboratories, Houston, TX, USA) were analysed together with the samples analysed for $\mathrm{Hb}$ and plasma ferritin respectively.

\section{Quantification of iron isotope in blood}

Each isotopically enriched blood sample was analysed in duplicate for its $\mathrm{Fe}$ isotopic composition as previously described by Walczyk et al. (1997). The blood samples were mineralised by microwave digestion using a mixture of $\mathrm{HNO}_{3}$ and $\mathrm{H}_{2} \mathrm{O}_{2}$. Fe was separated from the matrix by anion-exchange chromatography and a solvent-solvent extraction step into diethyl ether. Isotopic analyses were performed by negative thermal ionisation MS (Walczyk, 1997).

\section{Calculation of iron absorption}

The amounts of ${ }^{57} \mathrm{Fe}$ and ${ }^{58} \mathrm{Fe}$ isotopic labels in blood $14 \mathrm{~d}$ after the test-meal administrations were calculated based on the shift in $\mathrm{Fe}$ isotope ratios and on the amount of $\mathrm{Fe}$ circulating in the body. The calculations were based on the principles of isotope dilution and took into account that the Fe isotopic labels were not monoisotopic (Walczyk et al. 1997). Circulating Fe was calculated based on blood volume and $\mathrm{Hb}$ concentration (Kastenmayer et al. 1994). Blood volume calculations were based on height and weight according to Brown et al. (1962). For calculations of fractional $\mathrm{Fe}$ absorption, $80 \%$ incorporation of the absorbed $\mathrm{Fe}$ into erythrocytes was assumed (Hosein et al. 1967).

\section{Food analysis}

All test-meal components (infant cereal and milk powder, milk and yoghurt) were analysed for $\mathrm{Fe}$ and $\mathrm{Ca}$ by electrothermal-flame atomic absorption spectroscopy (SpectrAA 400; Varian, Mulgrave, Australia) after mineralisation by microwave digestion (MLS-Ethos plus; MikrowellenLabor-Systeme, Leutkirch, Switzerland) in a $\mathrm{HNO}_{3}-$ $\mathrm{H}_{2} \mathrm{O}_{2}$ mixture, using a standard addition technique to minimise matrix effects. Phytic acid in the infant cereal was determined by a modification of the Makower method (Makower, 1970) in which Ce replaced Fe in the precipitation step.

\section{Statistics}

Fractional $\mathrm{Fe}$ absorption values are presented as geometric means and standard deviations $(-1 \mathrm{SD},+1 \mathrm{SD})$. Student's paired $t$ test was used to evaluate absorption data within each study. Absorption values were logarithmically transformed before statistical analysis (Excel 2002; Microsoft Corporation, Redmond, WA, USA).

\section{Results}

None of the subjects were found to be anaemic $(\mathrm{Hb}<120 \mathrm{~g} / \mathrm{l})$. However, nine women had no $\mathrm{Fe}$ stores indicated by low plasma ferritin values $(<12 \mu \mathrm{g} / \mathrm{l})$.

The test meals in study 1 (infant cereal) contained $0.6 \mathrm{mg} \mathrm{Fe}(1.1 \mathrm{mg} \mathrm{Fe} / 100$ infant cereal, $0.15 \mathrm{mg} \mathrm{Fe} / 100 \mathrm{~g}$ milk powder), $167 \mathrm{mg} \mathrm{Ca}(148 \mathrm{mg} \mathrm{Ca} / 100 \mathrm{~g}$ infant cereal, $1159 \mathrm{mg} \mathrm{Ca} / 100 \mathrm{~g}$ milk powder) and $84 \mathrm{mg}$ phytic acid (168 mg phytic acid/100g infant cereal). The yoghurt drink served in study 2 contained $0.06 \mathrm{mg} \mathrm{Fe}(23 \mu \mathrm{g}$ $\mathrm{Fe} / 100 \mathrm{~g}$ unskimmed milk, $22 \mu \mathrm{g}$ Fe/100g unskimmed yoghurt), and $340 \mathrm{mg} \mathrm{Ca}(109 \mathrm{mg} \mathrm{Ca} / 100 \mathrm{~g}$ unskimmed milk, $137 \mathrm{mg} \mathrm{Ca} / 100 \mathrm{~g}$ unskimmed yoghurt). The ascorbic acid content was not measured as it was assumed to be negligible in both test meals.

There was no statistically significant difference between Fe absorption from the micronised, dispersible ferric pyrophosphate- and the ferrous sulfate-fortified infant cereal (geometric mean 3.4 and $4.1 \%$ respectively; $P=0.24$ ) (Table 1). There was also no statistically significant difference between $\mathrm{Fe}$ absorption from the micronised, dispersible ferric pyrophosphate- and the ferrous sulfate-fortified yoghurt drink (geometric mean 3.9 and $4.2 \%$ respectively; $P=0.72)$ (Table 2).

\section{Discussion}

When measuring Fe absorption from Fe fortification compounds using stable or radioisotope techniques it is extremely important that the physical and chemical properties of the labelled compounds are comparable with those of their commercial counterpart. In the case of ferrous sulfate, it is relatively easy to prepare a labelled compound with physical and chemical properties similar to commercially available ferrous sulfate. The production of labelled micronised, dispersible ferric pyrophosphate was however more complex. This was mainly due to the necessity to synthesise 
Table 1. Iron absorption by ten healthy adult women from infant cereal (study 1) fortified with ferrous sulfate or micronised, dispersible ferric pyrophosphate (Sunactive $\left.\mathrm{Fe}^{\mathrm{TM} *}\right)(5 \mathrm{mg}$ iron/meal)

\begin{tabular}{|c|c|c|c|c|c|}
\hline & \multirow[b]{2}{*}{ Plasma ferritin $(\mu \mathrm{g} / \mathrm{l})$} & \multirow[b]{2}{*}{$\mathrm{Hb}(\mathrm{g} / \mathrm{l})$} & \multicolumn{2}{|c|}{ Fe absorption (\%) } & \multirow[b]{2}{*}{ Relative bioavailability (\%)† } \\
\hline & & & $\begin{array}{l}\text { Micronised, dispersible } \\
\text { ferric pyrophosphate }\end{array}$ & $\begin{array}{l}\text { Ferrous } \\
\text { sulfate }\end{array}$ & \\
\hline \multicolumn{6}{|l|}{ Subject no. } \\
\hline 1 & 6.9 & 129 & 4.5 & 8.7 & 52 \\
\hline 2 & $11 \cdot 0$ & 136 & $1 \cdot 8$ & $2 \cdot 4$ & 75 \\
\hline 3 & $19 \cdot 8$ & 130 & $3 \cdot 1$ & 4.4 & 70 \\
\hline 4 & $56 \cdot 5$ & 140 & 1.5 & 1.9 & 78 \\
\hline 5 & $15 \cdot 8$ & 149 & 3.3 & 5.4 & 61 \\
\hline 6 & $9 \cdot 1$ & 127 & 3.4 & 1.8 & 187 \\
\hline 7 & 11.8 & 142 & 4.4 & 8.0 & 55 \\
\hline 8 & 11.9 & 138 & $6 \cdot 4$ & $3 \cdot 1$ & 205 \\
\hline 9 & $20 \cdot 8$ & 150 & $2 \cdot 4$ & 3.3 & 72 \\
\hline 10 & 7.4 & 132 & $6 \cdot 9$ & $9 \cdot 3$ & 75 \\
\hline Geometric mean & & & 3.4 & $4 \cdot 1$ & 83 \\
\hline$-S D$ & & & $2 \cdot 2$ & $2 \cdot 2$ & 51 \\
\hline$+\mathrm{SD}$ & & & $5 \cdot 6$ & $7 \cdot \overline{6}$ & 133 \\
\hline
\end{tabular}

*Taiyo Kagaku, Yokkaichi, Japan.

†Fe absorption from ferrous sulfate $=100 \%$.

Table 2. Iron absorption by ten healthy adult women from yoghurt drink (study 2) fortified with ferrous sulfate or micronised, dispersible ferric pyrophosphate (Sunactive $\left.\mathrm{Fe}^{\mathrm{TM} *}\right)(5 \mathrm{mg}$ iron/meal)

\begin{tabular}{|c|c|c|c|c|c|}
\hline & \multirow[b]{2}{*}{ Plasma ferritin $(\mu \mathrm{g} / \mathrm{l})$} & \multirow[b]{2}{*}{$\mathrm{Hb}(\mathrm{g} / \mathrm{l})$} & \multicolumn{2}{|c|}{ Fe absorption (\%) } & \multirow[b]{2}{*}{ Relative bioavailability (\%)† } \\
\hline & & & $\begin{array}{l}\text { Micronised, dispersible } \\
\text { ferric pyrophosphate }\end{array}$ & $\begin{array}{l}\text { Ferrous } \\
\text { sulfate }\end{array}$ & \\
\hline \multicolumn{6}{|l|}{ Subject no. } \\
\hline 11 & 20.9 & 141 & $1 \cdot 1$ & $2 \cdot 7$ & 41 \\
\hline 12 & $41 \cdot 1$ & 143 & $2 \cdot 4$ & $2 \cdot 7$ & 88 \\
\hline 13 & 7.9 & 129 & $5 \cdot 3$ & $6 \cdot 0$ & 89 \\
\hline 14 & $28 \cdot 6$ & 134 & 4.7 & $2 \cdot 0$ & 237 \\
\hline 15 & 9.7 & 129 & $14 \cdot 0$ & $20 \cdot 0$ & 70 \\
\hline 16 & $16 \cdot 2$ & 152 & $5 \cdot 9$ & $5 \cdot 2$ & 114 \\
\hline 17 & 7.9 & 129 & $8 \cdot 1$ & 11.6 & 70 \\
\hline 18 & $79 \cdot 3$ & 131 & 0.5 & 0.8 & 66 \\
\hline 19 & 23.9 & 145 & $7 \cdot 1$ & 4.0 & 180 \\
\hline 20 & $28 \cdot 4$ & 142 & $5 \cdot 3$ & 4.8 & 109 \\
\hline Geometric mean & & & 3.9 & 4.2 & 94 \\
\hline$-S D$ & & & 1.5 & 1.7 & 56 \\
\hline$+\mathrm{SD}$ & & & $10 \cdot 5$ & $10 \cdot 3$ & 157 \\
\hline
\end{tabular}

*Taiyo Kagaku, Yokkaichi, Japan.

†Fe absorption from ferrous sulfate $=100 \%$.

ferric trichloride in the hexahydrate form from isotopically enriched metal, free of acid residues and iron oxides. The labelled micronised, dispersible ferric pyrophosphate was made using a down-scaled manufacturing procedure similar to the commercial production procedure and the resulting compound was found to have a similar particle-size distribution as the commercial compound (Fig. 1).

The results of the present studies showed that micronised, dispersible ferric pyrophosphate is as well absorbed as ferrous sulfate from a wheat-based infant cereal as well as from a yoghurt drink. In previous studies with adult subjects, ferric pyrophosphate has been reported to have a relative bioavailability (RBV) compared with ferrous sulfate (RBV $100 \%$ ) varying from 15 to $75 \%$. In infant cereals, the values reported were between 15 and $39 \%$ (Hurrell et al. 1989, 1991, 2000). The high RBV of Fe from micronised, dispersible ferric pyrophosphate, as demonstrated in the present study, is probably related to the extremely small particle size of the Fe compound which is approximately twenty times smaller than regular ferric pyrophosphate (average particle size $7.5 \mu \mathrm{m}$; Fig. 1). In rat studies, decreasing the particle size of water-insoluble $\mathrm{Fe}$ compounds has previously been shown to have a positive influence on $\mathrm{Fe}$ absorption. Shah \& Belonje (1973), for example, showed that the $\mathrm{RBV}$ of electrolytic $\mathrm{Fe}$ powder increased from 12 to $32 \%$ when the proportion of particles below $10 \mu \mathrm{m}$ was increased from 62 to $99 \%$. Further, Motzok et al. (1975) demonstrated that decreasing particle size of $\mathrm{CO}$-reduced $\mathrm{Fe}$ powders from $24-40 \mu \mathrm{m}$ to $7-10 \mu \mathrm{m}$ increased RBV from 11 to $31 \%$. Fe absorption from ferric orthophosphate has also been shown to be dependent on particle size as 
RBV increased nearly 8-fold (from 6 to $46 \%$ ) when particle size was decreased from approximately $15 \mu \mathrm{m}$ to below $1 \mu \mathrm{m}$ (Harrison et al. 1976). In human subjects, Björn-Rasmussen et al. (1977) reported that Fe absorption from hydrogen-reduced elemental $\mathrm{Fe}$ powders was dependent on their solubility in dilute acid, which in turn was partly dependent on particle size and active surface area. In the present study, it was not technically feasible to produce labelled ferric pyrophosphate with the same particle size distribution as Sunactive $\mathrm{Fe}^{\mathrm{TM}}$ without the addition of emulsifiers. Therefore, we were not able to evaluate if the high RBV of micronised, dispersible ferric pyrophosphate was only due to the small particle size or whether the emulsifiers influenced Fe absorption significantly.

Based on the results from the present studies, micronised, dispersible ferric pyrophosphate could be a very useful Fe fortificant, especially since it can be expected to cause fewer organoleptic problems than water-soluble $\mathrm{Fe}$ compounds. Extensive organoleptic studies, however, still remain to be carried out. Presently, Sunactive $\mathrm{Fe}^{\mathrm{TM}}$ is being used in Japan to fortify milk and milk products. Milk products have previously been shown to be difficult to fortify with readily absorbable Fe due to organoleptic problems (Demott, 1971; Edmondson et al. 1971; Kurtz et al. 1973; Wang \& King, 1973). Fe fortificants that have been shown to be suitable for fluid milk fortification include ferric ammonium citrate, ferrous bisglycinate and encapsulated ferrous sulfate (Edmondson et al. 1971; Wang \& King, 1973; Boccio et al. 1997; Olivares et al. 1997). While ferrous bisglycinate would be expected to be at least as well absorbed as ferrous sulfate (Fox et al. 1998), if not better (Bovell-Benjamin et al. 2000; Layrisse et al. 2000), ferric ammonium citrate has been reported to be less well absorbed than ferrous sulfate (Grebe et al. 1975; Layrisse et al. 1976; Gonzalez et al. 2001).

In addition to milk products, micronised, dispersible ferric pyrophosphate is potentially a suitable Fe fortificant for food vehicles that are difficult to fortify with readily available Fe such as chocolate-drink powders, cereal products, iodised salt, and bouillon cubes. Further, the overall acceptability of simulated rice grains (Kapanidis \& Lee, 1996) may be improved by using micronised, dispersible ferric pyrophosphate instead of ferrous sulfate as less discoloration of fortified rice grains can be expected.

Although not statistically different, absorption from micronised, dispersible ferric pyrophosphate relative to ferrous sulfate was somewhat lower from the infant cereal than from the yoghurt drink in the present study (Tables 1 and 2). The differences in relative $\mathrm{Fe}$ absorption from different meals could be related to the differences in the dissolution of micronised, dispersible ferric pyrophosphate in the gastric juice as well as gastric emptying rate which both depend on meal composition (Hallberg et al., 1986). Further studies are needed to evaluate the RBV of micronised, dispersible ferric pyrophosphate added to different food vehicles.

In conclusion, the results of the present studies show that Fe absorption from micronised, dispersible ferric pyrophosphate (Sunactive $\mathrm{Fe}^{\mathrm{TM}}$ ) is similar to that of ferrous sulfate from a fortified infant cereal as well as from a fortified yoghurt drink. The high RBV is presumably due to the very small particle size. Micronised, dispersible ferric pyrophosphate can be expected to provoke fewer unacceptable sensory changes than water-soluble Fe compounds in different food vehicles; however, comprehensive sensory studies are now needed to fully evaluate the usefulness of this compound.

\section{Acknowledgement}

The study was supported financially by Taiyo Kagaku, Yokkaichi, Japan.

\section{References}

Björn-Rasmussen E, Hallberg L \& Rossander L (1977) Absorption of 'fortification' iron. Bioavailability in man of different samples of reduced $\mathrm{Fe}$, and prediction of the effects of Fe fortification. Br J Nutr 37, 375-388.

Boccio JR, Zubillaga MB, Caro RA, Gotelli CA, Gotelli MA \& Weil R (1997) A new procedure to fortify fluid milk and dairy products with high bioavailable ferrous ferrous sulphate. Nutr Rev 55, 240-246.

Bovell-Benjamin AC, Viteri FE \& Allen LH (2000) Iron absorption from ferrous bisglycinate and ferric trisglycinate in whole maize is regulated by iron status. Am J Clin Nutr 71, $1563-1569$.

Brown E, Hopper J Jr, Hodges J Jr, Bradley B, Wennesland R \& Yamauchi H (1962) Red cell, plasma and blood volume in healthy women measured by radiochromium cell-labeling and hematocrit. J Clin Invest 41, 2182-2190.

Demott BJ (1971) Effects on flavor of fortifying milk with iron and absorption of the iron from intestinal tract of rats. J Dairy Sci 54, 1609-1614.

Edmondson LF, Douglas FW Jr \& Avants JK (1971) Enrichment of pasteurized whole milk with iron. J Dairy Sci 54, $1422-1426$

Fox TE, Eagles J \& Fairweather-Tait SJ (1998) Bioavailability of iron glycine as a fortificant in infant foods. Am J Clin Nutr $\mathbf{6 7}$, 664-668.

Gonzalez H, Mendoza C \& Viteri FE (2001) Absorption of unlabeled reduced iron of small particle size from a commercial source. A method to predict absorption of unlabeled iron compounds in humans. Arch Latinoam Nutr 51, 217-224.

Grebe G, Martinez-Torres C \& Layrisse M (1975) Effect of meals and ascorbic acid on the absorption of a therapeutic dose of iron as ferrous and ferric salts. Curr Ther Res Clin Exp 17, 382-397.

Hallberg L, Brune M \& Rossander L (1986) Low bioavailability of carbonyl iron in man: studies on iron fortification of wheat flour. Am J Clin Nutr 43, 59-67.

Harrison BN, Pla GW, Clark GA \& Fritz JC (1976) Selection of iron sources for cereal enrichment. Cereal Chem 53, 78-84.

Hosein F, Marsaglia G \& Finch CA (1967) Blood ferrokinetics in normal man. J Clin Invest 49, 1-9.

Hurrell RF (1997) Preventing iron deficiency through food fortification. Nutr Rev 55, 210-222.

Hurrell RF (1998) Improvement of trace element status through food fortification: technological, biological and health aspects. Bibl Nutr Dieta 40-57.

Hurrell RF \& Cook JD (1990) Strategies for iron fortification of foods. Trends Food Sci Technol 1, 56-61.

Hurrell RF, Furniss DE, Burri J, Whittaker P, Lynch SR \& Cook JD (1989) Iron fortification of infant cereals: a proposal 
for the use of ferrous fumarate or ferrous succinate. Am J Clin Nutr 49, 1274-1282.

Hurrell RF, Reddy MB, Burri J \& Cook JD (2000) An evaluation of EDTA compounds for iron fortification of cereal-based foods. Br J Nutr 84, 903-910.

Hurrell RF, Reddy MB, Dassenko SA \& Cook JD (1991) Ferrous fumarate fortification of a chocolate drink powder. $\mathrm{Br} J$ Nutr 65, 271-283.

Juneja LR, Nakata H, Sakaguchi N \& Nanbu H (2003) A new concept of ferric pyrophosphate fortification in foods (Sunactive $\mathrm{Fe}^{\mathrm{TM}}$ ). 2003 INACG Symposium, 41. http://inacg.ilsi.org/file/ inacg.pdf

Kapanidis AN \& Lee TC (1996) Novel method for the production of color-compatible ferrous sulfate-fortified simulated rice through extrusion. J Agric Food Chem 44, 522-525.

Kastenmayer P, Davidsson L, Galan P, Cherouvrier F, Hercberg S \& Hurrell RF (1994) A double stable isotope technique for measuring iron absorption in infants. Br J Nutr 71, 411-424.

Kurtz FE, Tamsma A \& Pallansch MJ (1973) Effect of fortification with iron on susceptibility of skim milk and nonfat dry milk to oxidation. J Dairy Sci 56, 1139-1143.

Layrisse M, Garcia-Casal MN, Solano L, et al. (2000) Iron bioavailability in humans from breakfasts enriched with iron bis-glycine chelate, phytates and polyphenols. J Nutr 130, 2195-2199.
Layrisse M, Martinez-Torres C \& Renzi M (1976) Sugar as a vehicle for iron fortification: further studies. Am J Clin Nutr 29, 274-279.

Makower RU (1970) Extraction and determination of phytic acid in beans (phaeolus vulgaris). Cereal Chem 47, 288-295.

Motzok I, Pennell MD, Davies MI \& Ross HU (1975) Effect of particle size on the biological availability of reduced iron. J Assoc Official Anal Chem 58, 99-103.

Nanbu H, Nakata K, Sakaguchi N \& Yamazaki Y (1998) Mineral Composition. European Patent EP 0870435A1.

Olivares M, Pizarro F, Pineda O, Name JJ, Hertrampf E \& Walter T (1997) Milk inhibits and ascorbic acid favors ferrous bis-glycine chelate bioavailability in humans. J Nutr 127, 1407-1411.

Shah BG \& Belonje B (1973) Bio-availability of reduced iron. (food additives). Nutr Rep Int 7, 151-156.

Walczyk T (1997) Iron isotope ratio measurements by negative thermal ionization mass spectrometry. Int J Mass Spectrom Ion Proc 161, 217-227.

Walczyk T, Davidsson L, Zavaleta N \& Hurrell RF (1997) Stable isotope labels as a tool to determine iron absorption by Peruvian school children from a breakfast meal. Fresenius J Anal Chem 359, 445-449.

Wang CF \& King RL (1973) Chemical and sensory evaluation of iron-fortified milk. J Food Sci 38, 938-940. 